\title{
Journal of Dairy Science 2014 Editorial Report
}

\author{
Matthew Lucy, Editor-in-Chief ${ }^{1}$ \\ University of Missouri, Columbia
}

\section{Introductory Comments}

The Journal of Dairy Science ${ }^{\circledR}$ is the longest-running scientific periodical in animal and veterinary sciences, with its inaugural issue published in 1917. From the time of its inception, the Journal of Dairy Science has maintained unprecedented status as a leader in the publication of research articles in dairy foods and dairy production. As incoming editor-in-chief (EIC), I am honored to be part of the large team, including editors, authors, reviewers, and staff, that maintains the historical excellence of this prestigious journal.

\section{Recognition for Service}

My term as EIC began in August 2014. I would like to recognize the outstanding term of Roger Shanks (outgoing EIC). Roger oversaw a period of unprecedented growth at JDS. His term will be viewed as historic in years to come. My task is to attempt to maintain the tremendous legacy that was left by Roger as well as other past EICs of JDS.

In the FASS office, I interact primarily with Susan Pollock (managing editor), Louise Adam (lead technical editor), and Shauna Miller (editorial assistant). My job as EIC could not be done without the outstanding efforts of these individuals. There are additional individuals on the FASS publications staff that I do not interact with daily but these individuals should be recognized for their efforts in making JDS a success. I would like to personally thank Jorge Cazares, Chris Davies, Sharon Frick, Gayle Gleichman, Christine Horger, Ron Keller, and Lisa Krohn. Of note, Gayle Gleichman retired in February after 37 years of service to ADSA and FASS. We could not publish such a large amount of scientific information in a consistently readable format without these individuals.

The scientific quality of the Journal of Dairy Science arises from the quality of the section editors who

Received February 9, 2015.

Accepted February 9, 2015.

${ }^{1}$ Corresponding author: lucym@missouri.edu serve our journal. Their decisions ultimately dictate the long-term success or failure of the journal. Three section editors completed their terms in 2014: Geoff Dahl (University of Florida) and Rupert Bruckmaier (University of Bern) from Physiology and Management and Georgios Banos (Roslin Institute) from Genetics and Breeding. These individuals are good friends and their outstanding service is recognized here.

Kerst Stelwagen (SciLactis Ltd; Physiology and Management) and Christa Kuhn (Leibniz Institute for Farm Animal Biology; Genetics and Breeding) joined John Vicini (Monsanto; Nutrition, Feeding, and Calves) and MaryAnne Drake (North Carolina State University; Dairy Foods) as senior editors in 2014. Invited reviews are handled by Filippo Miglior (Canadian Dairy Network/University of Guelph).

We added new section editors in 2014, including Normand St-Pierre (Ohio State University) and Tanya Gressley (University of Delaware) in Physiology and Management, and Christian Maltecca (North Carolina State University) in Genetics and Breeding. I thank these individuals for accepting the invitation for this important task.

Remaining section editors (not mentioned above) include Phil Tong (Cal Poly State University) and John McKillip (Ball State University) in Dairy Foods; David Beede (Michigan State) and Helga Sauerwein (University of Bonn) in Physiology and Management; John Roche (DairyNZ), Masahito Oba (University of Alberta), and Paul Kononoff (University of Nebraska) in Nutrition, Feeding, and Calves; and Jennie Pryce (Department of Primary Industries, Australia) in Genetics and Breeding. Each of these editors continues to make valuable contributions to the success of the journal.

The editorial board included 45 members in 2014 . Editorial board members are expected to have additional expertise and to review considerably more manuscripts than the traditional reviewer for the journal. Their service provides a second layer of excellence directly below the section editors.

We sent out more than 1,800 letters to recognize the reviewers who served JDS in 2014. Our reviewers play a big part in keeping the days from submission to first 
decision low while providing excellent feedback to our authors. Their efforts ensure that our excellent time to publication and high scientific standards for accepted manuscripts will continue. The time that our reviewers have so generously contributed is very much appreciated.

\section{Year in Review-The Numbers}

As of 2014, the Journal of Dairy Science ranked second for Impact Factor (2.55) and second by 5 -Year Impact Factor (3.08) among 51 journals in the Agriculture, Dairy and Animal Science category. The Impact Factor statistics or ranking did not change appreciably from 2013.

We published 8,058 pages in the Journal of Dairy Science in 2014 (Table 1). This number of pages is about equal to that published in 2013 (8,134 pages). We did publish more papers in 2014 than 2013. Average time from submission to having an article "in press" did not change from 2013 (6 months). In my opinion, most authors would consider this a very acceptable time from submission to being available online. Time to print production was slightly longer (7.5 months) but still acceptable. Credit for these very good numbers goes to our editors, reviewers, authors, and staff. We have our production time to a minimum at this point. Improvements in time to publication will need to be realized through a more timely peer-review process. If we compare these numbers with those from 2006, we are publishing over $50 \%$ more papers with a shorter average time to production. Percentage of published papers compared with received papers has not changed appreciably since 2006.

Of 1,333 decisions made in 2014, 797 submissions were accepted and 536 were rejected, for an acceptance rate of $60 \%$. This is up slightly from the $58 \%$ acceptance rate for 1,318 decisions made during 2013.

During both 2013 and 2014, international submissions (from outside the United States and Canada) comprised approximately $68 \%$ of total submissions (Canada $=110$ submissions or $7.9 \%$; US $=340$ submissions or $24.3 \%$ of total). Decisions were made during 2014 on submissions from 59 countries, and accepted submissions were received from 46 countries. The top three countries for submissions were United States (340), China (142), and Canada (110). The top three countries for accepted papers were United States (268), Canada (68), and Italy (52).

Most papers (about 85\%) are published as research articles (Table 2). About $5 \%$ of our papers are "Our Industry Today" and "Short Communications". Invited reviews comprise only $2.5 \%$ of our papers but have twice the number of citations compared with papers of other types.

About $35 \%$ of the papers that we publish are in Physiology and Management (Table 3). The second largest section (about 30\% of papers) is Nutrition, Feeding, and Calves. Dairy Foods publishes about $22 \%$ of papers, and Genetics and Breeding publishes about $10 \%$ of our papers. Although we publish the fewest papers in Genetics and Breeding, a recent analysis of citations demonstrated that research papers in Genetics and Breeding had more citations and consequently have a greater influence on our Impact Factor than papers in the other sections for manuscripts.

\section{Continuing Efforts to Recognize Authors}

We are continuing several efforts initiated during Roger Shank's tenure as EIC. One research paper is featured in each issue and three research papers are highlighted. Papers are selected by the EIC when the issue is proofed before publication. Selected papers are novel, topical, and contain solid science. I attempt to recognize article published in different sections but a single section may not be represented every month. Featured and highlighted articles are featured on the

Table 1. Journal of Dairy Science statistics for 2014 compared with previous years

\begin{tabular}{|c|c|c|c|c|c|c|c|c|c|}
\hline & 2014 & 2013 & 2012 & 2011 & 2010 & 2009 & 2008 & 2007 & 2006 \\
\hline Avg. papers received/mo & 117 & 112 & 102 & 97 & 87 & 86 & 85 & 79 & 74 \\
\hline Avg. papers accepted/mo & 66 & 64 & 63 & 55 & 56 & 49 & 48 & 46 & 46 \\
\hline Avg. papers published $/ \mathrm{mo}$ & 65 & 65 & 62 & 55 & 52 & 53 & 44 & 52 & 45 \\
\hline Pages published & 8,058 & 8,134 & 7,466 & 6,298 & 6,064 & 6,306 & 5,134 & 5,849 & 4,961 \\
\hline Average review time (d) & 137 & 139 & 141 & 144 & 140 & 127 & 141 & 127 & 125 \\
\hline Avg. production time $(\mathrm{d})^{*}$ & 89 & 87 & 105 & 93 & 94 & 107 & 102 & 106 & 126 \\
\hline Average total time (d) & 226 & 226 & 246 & 237 & 234 & 234 & 243 & 233 & 251 \\
\hline Average in press (d) & 49 & 47 & 60 & - & - & - & - & - & - \\
\hline
\end{tabular}

*Print production. 
Table 2. Journal of Dairy Science manuscript and page statistics by article type for 2014

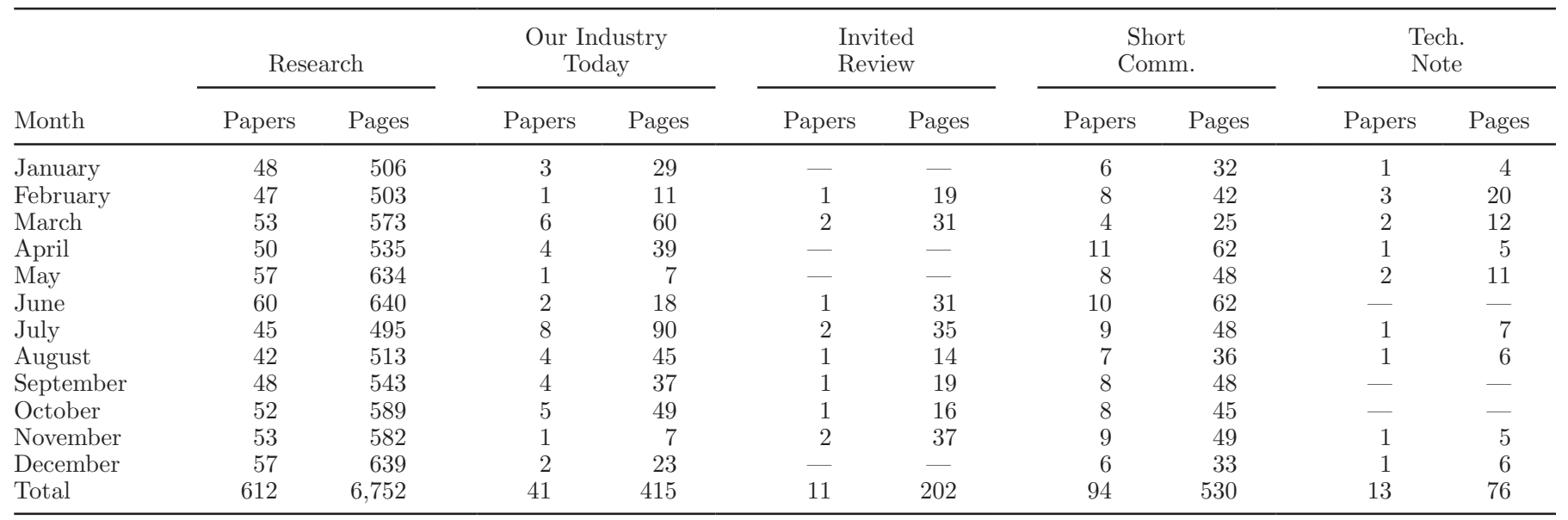

Table does not include hot topics, letters, errata, news, or editorial.

homepage of the JDS website for one month. Authors receive a letter from the EIC recognizing their submission.

Awards for the most highly cited manuscripts continued during 2014. Four authors of papers published in 2011 were recognized at the 2014 ADSA Awards Ceremony for authoring the most cited papers in each section of the journal. Papers published in JDS during the calendar year 2012 are eligible for recognition at the 2015 ADSA Awards Ceremony.

We are continuing the member-author loyalty reward program that was initiated in 2014. This program recognizes ADSA member-authors who publish in JDS and review for JDS. Authors meeting the specific criteria receive a waiver for page charges (10-page limit) that can be used for their next JDS publication.

\section{New Initiatives Begun in 2014}

As incoming EIC, I felt that it was necessary to meet monthly at FASS headquarters with Susan and Louise so that we could become better acquainted. During these monthly meetings, we have done some long-term planning for the journal. Roger Shanks (past EIC; University of Illinois), Dave Beede (PM Section Editor; Michigan State), John Vicini (NFC Section Editor; Monsanto), and Mike Miller (Journal Management Committee; University of Illinois) have each attended one of those monthly meetings. Two initiatives that arose from those monthly meetings were (1) expansion of the editorial board and redefining responsibilities, and (2) creation of a job description for JDS Section Editors.

Table 3. Journal of Dairy Science research manuscripts and page statistics by science section ${ }^{1}$ for 2014

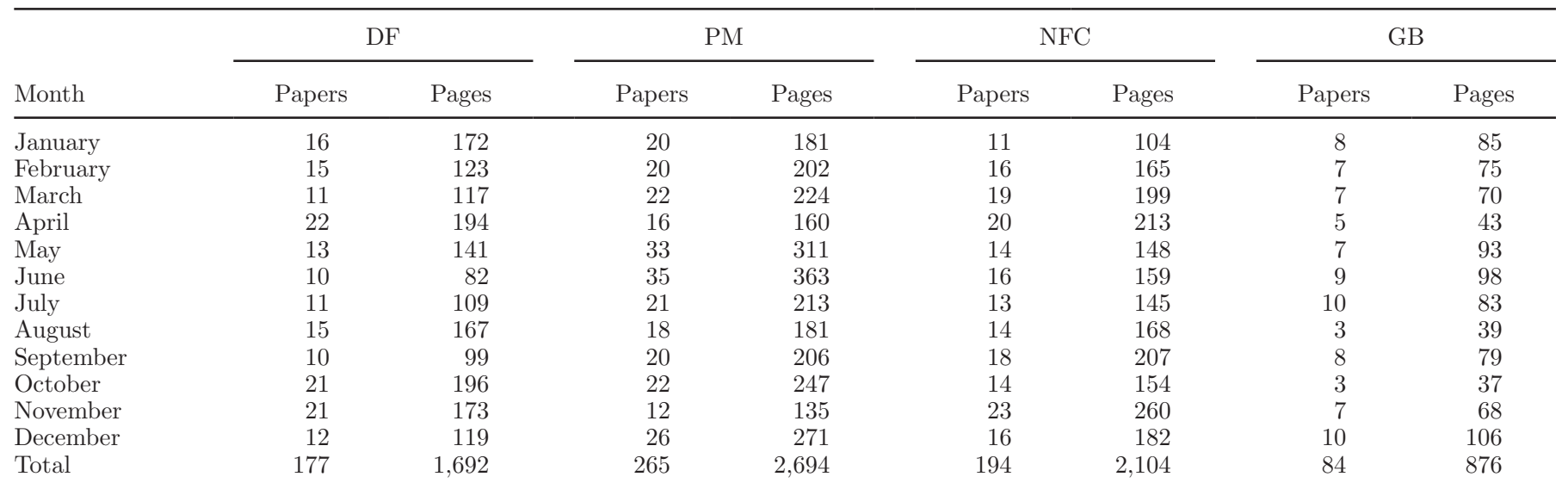

${ }^{1} \mathrm{DF}=$ Dairy Foods; PM = Physiology and Management; NFC = Nutrition, Feeding, and Calves; and GB = Genetics and Breeding. Table does not include Our Industry Today manuscripts or invited reviews. 
Other planned initiatives include

(1) Major improvements and updates to the JDS website.

(2) Improvements to existing features that authors can use to track downloads and citations of their papers.

(3) Innovative methods to promote content including collections and audio slides.

(4) Development of a plan for marketing for the journal that includes traditional methods and social media.

\section{Impact Factor}

The Impact Factor for JDS remains at about 2.5. Although this is a very acceptable number, we would like to keep this number moving upward.

\section{Concluding Comments}

It is a great pleasure to serve JDS as the EIC. I am looking forward to the continued success of the journal. 